\title{
ON THE REINSPIRATION OF EXPIRED AIR *
}

THOMAS R. CROWDER, M.D.

CHICAGO

I desire to record a phenomenon and to discuss its significance.

The phenomenon is, the immediate reinspiration of a portion of our expired air. This occurs quite commonly - so commonly, in fact, that it is an accompaniment of respiration during the major part of the lives of many people, and during a large part of the lives of practically all.

The observation of this phenomenon is not new. Lehmann ${ }^{1}$ and Heymann ${ }^{2}$ have each reported a small group of experiments, in which they determined the carbon dioxid of the inspired air, compared this with the carbon dioxid of the surrounding air, and from the difference computed the proportion of the breath which was reinspired. The proportion varied greatly. It was sometimes more than 6 per cent.; it dropped to zero in the open air and in a breeze of 3 meters per second.

A few years ago this subject attracted my attention in connection with certain studies of ventilation. The experiments of Lehmann and Heymann demonstrated little except that reinspiration may and does occur. It seemed desirable to carry the observations further. As opportunity arose this has been done, and an attempt has been made to determine some of the factors controlling this phenomenon. The work has included the analysis of about 900 samples of inspired air.

\section{METHODS}

In order to find what proportion of the expired air re-enters the respiratory tract with the succeeding inspiration, it is necessary to collect samples of the inspired air as it enters the nasal passages and subject them to analysis. The only difficulty in collecting the samples arises through the possibility of including a portion of the expired air as it leaves the nasal passages. This is likely to occur if the taking of the sample is not accurately timed to the inspiratory period; collection must begin after inspiration is established and must end before expiration has begun.

Experiments such as these are more readily carried out on oneself than on a second person, because of the easier identification of the

* Submitted for publication July 15, 1913.

1. Lehmann: Der Kohlensäuregehalt der Inspirationsluft im Freien und im Zimmer, Arch. f. Hyg., 1899, xxxiv, 315.

2. Heymann: Ueber den Einfluss wieder eingeathmeter Expirationsluft auf die Kohlensäure-Abgabe, Ztschr. f. Hyg., 1905, xlix, 388. 
respiratory periods. With a little practice one may become perfectly conscious of the beginning and end of inspiration; and with a little more practice may learn to bring the inlet tube of a bellows into the nasal orifice at the proper moment and to remove it at the proper moment, using one hand meanwhile to manipulate the bellows. By arranging for an air current that will immediately carry away all of the expired air, a series of controls may be run that will show clearly when the technic is mastered. The observations herewith recorded were made by the author on himself. Those made by the experimenters above referred to were made on a second person.

After various trials of more or less complicated apparatus, a very simple plan of collecting samples was adopted. The ordinary Paquelin cautery bulb was found to answer very well for this purpose after a little alteration. The only necessary alterations are a long rubber tube with

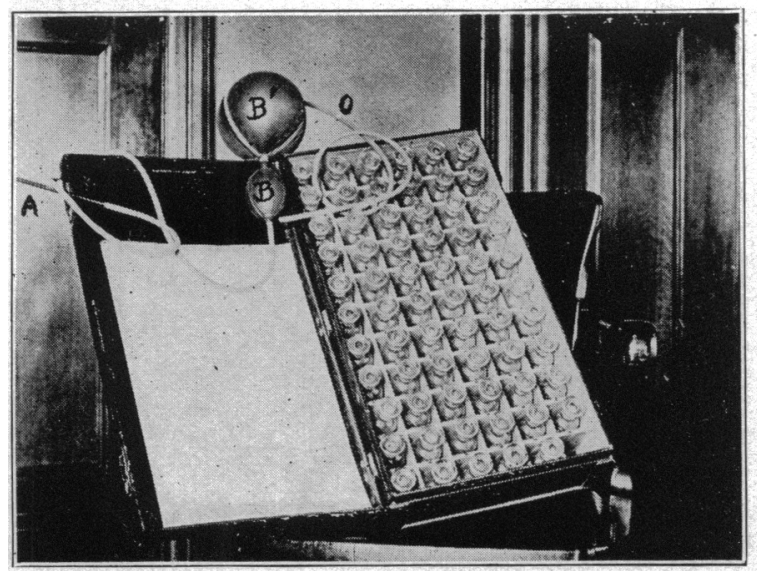

Fig. 1.-Apparatus used in collecting samples of air. $A$, intake tube; $B$, bellows; $B^{\prime}$, the elastic bag; $O$, outlet tube.

a glass tip attached to the bellows intake, and a pinch-cock applied to the outlet tube from the elastic bag. A somewhat larger and heavier bag than that ordinarily supplied with the cautery was used, but the arrangemeit was essentially the same. 'The accompanying photograph (Fig. 1) shows the apparatus used, and the case for collecting and carrying samples and records. $A$ is the intake tube, $B$ is the bellows, $B^{\prime}$ the elastic bag and $O$ the outlet tube.

After inspiration is well established the glass inlet tube is brought just within the nasal orifice - or between the parted lips during mouth breathing - and the bellows given two or three quick compressions. The inlet tube is removed during expiration and is again brought into place 
during the succeeding inspiration. This is repeated during eight or ten breaths, or until about 1,000 cubic centimeters of air have been collected in the bag. 'The outlet tube is then thrust to the bottom of a two-ounce bottle and the air run through it by releasing the pinch-cock. This leaves the sample of air in the bottle. On withdrawal of the tube a waxed glass stopper is inserted and the seal made perfect. If the bottle is clean and dry there will be no change in the air it contains for a fortnight or more. The samples are then transferred under a saturated solution of sodium. chlorid to a Petterson-Palmquist apparatus and analyzed for carbon dioxid. The details of the various steps, the necessary precautions and the accuracy of the method have been previously discussed. ${ }^{3}$

At the time the samples of inspired air are collected, samples of the surrounding air must also be taken. The amount of immediate reinspiration is measured by the difference in the carbon dioxid content of these two. In the accompanying charts this difference is shown directly, and the proportion of $\mathrm{CO}_{2}$ in the air is expressed in ten-thousandths of the whole rolume. In the text, reinspiration is referred to in terms of pel cent.; that is, the proportion of expired air which is mixed with the inspired air and which is therefore reinhaled after it has been once expelled. It may be assumed that for every 4.5 per 10,000 difference between the $\mathrm{CO}_{2}$ of the inspired air and of the surrounding air, 1 per cent. of the expired air is being reinspired. This is derived by a very simple computation, based on the fact that the expired air contains about 450 volumes of $\mathrm{CO}_{2}$ in 10,000 volumes of air. It will of course vary a little from this figure, which is an average, but the variation will be relatively small and will affect the computation only slightly.

It should be remembered that the normal air contains 3.5 to 4 parts of $\mathrm{CO}_{2}$ per 10,000 . All above this is contamination, the result of respiration, burning lights, or other chemical processes. In the majority of instances all $\mathrm{CO}_{2}$ above 4 per 10,000 represents respiratory contamination; and in a broad sense all $\mathrm{CO}$, above 4 per 10,000 in the inspired air generally represents reinspiration. But for our present purpose we shall consider only the $\mathrm{CO}_{2}$ which is in excess of the amount contained in the general surrounding air; for it is this portion only which represents that strictly local contamination which leads to the immediate reinspiration of our exhalations now under discussion.

\section{RESULTS}

It was soon noticed that, under apparently fixed conditions, repeated observations of the inspired air would always show considerable variation

3. Crowder: A Study of the Ventilation of Sleeping Cars, The ARchives JNT. MED., 1911, vii, 85. 
in the $\mathrm{CO}_{2}$ content. All experiments were therefore carried out with serial tests, including from 4 to 24 successive samples, in order to arrive at averages. 'The individual observations of such series can be made at about one minute intervals when one is standing or sitting. They will fall a little farther apart when lying down, or under any circumstances which oceasion interference with the easy manipulation of the apparatus and the records.

It proved desirable to alter the surrounding conditions, especially the amount of rentilation, at the same time and place, or to induce artificial air currents, and observe the effects on the phenomenon under investigation by running parallel series of tests. The effect of changes of position, body motion, different types of breathing, different temperatures and different degrees of contamination of the surrounding air were also investigated; and finally, the question of whether or not reinspiration takes place in such half-sheltered places as the sleeping-porch and in the open air. The results will follow in order. Unless otherwise specified, nasal breathing is referred to.

\section{THE AIR ABOUT THE FACE}

If the conditions are such that reinspiration can take place the air about the face will necessarily be found to contain more $\mathrm{CO}_{2}$ than the surrounding air. It is on the fact that the expired air is not immediately removed or disseminated that reinspiration depends. That it remains about the face for an appreciable interval, is easily demonstrated. This is illustrated in Figure 2 .

The heavy horizontal line in this, as in succeeding charts, represents the $\mathrm{CO}_{2}$ in the general air of the room. It was constant to within half a point of 4.5 per 10,000 . This half a point in 10,000 , or 1 in 20,000 , may be considered as about the maximum necessary error of the determinations. The series of samples represented by the upper curve, marked $A$, were taken close to the nose while holding the breath at the end of normal expiration; they contain an average of 3.8 per cent. of expired air. Those represented by the lower curve, marked $B$, were taken at the same place while holding the breath at the end of normal inspiration; they contain an a verage of 0.9 per cent. of expired air. The time occupied in collecting each of these samples was about five seconds. Those represented by the middle curve, marked $C$, were taken from within the nasal orifice during inspiration; they, therefore, show the contamination of the inspired air, which areraged 7.5 more $\mathrm{CO}_{2}$ per 10,000 than was contained in the air of the room. This excess of $\mathrm{CO}_{2}$ represents 1.7 per cent. of expired air; we therefore have for this series 1.7 per cent. of reinspiration. The average for each series is shown by the short horizontal line at the right. This experiment was carried out while sitting in 
a well-ventilated room of 3,000 cubic feet capacity, having three windows and three doors. The temperature was $73 \mathrm{~F}$.

A little variation of the last experiment will show that this local contamination reaches a considerable distance below the face, and that it decreases with increasing distance. Figure 3 illustrates some of the results with such a variation. At $A$ is shown a series of samples taken close to the body and 6 to 8 inches below the nose during expiration;

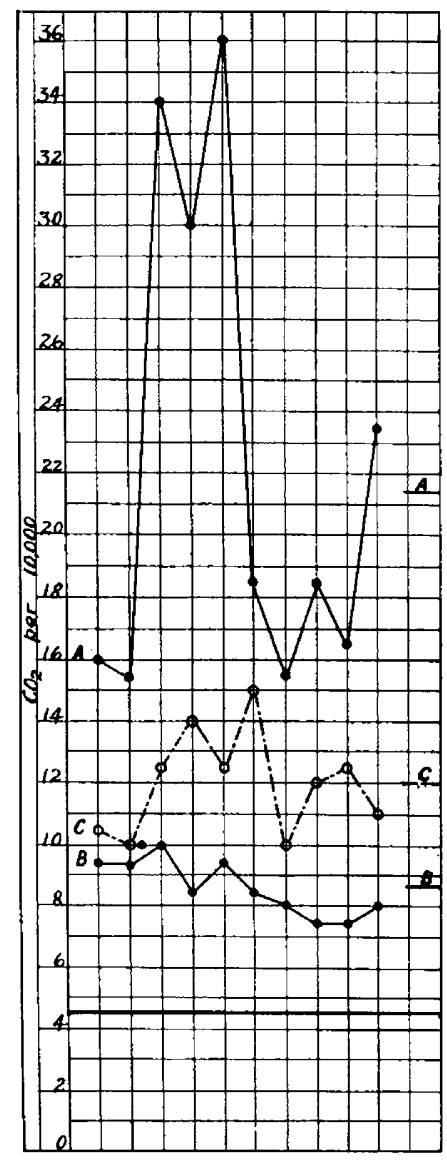

Fig. 2.-(Exper. 22). Showing contamination of the air about the face while holding the breath after expiration $(A)$, after inspiration $(B)$, and of the inspired air $(C)$.

they contain an arerage of 4.6 per cent. of expired air. At $B$ is shown a series taken 12 to 15 inches below the nose during expiration, and they contain 2.8 per cent. of expired air. At $C$ the samples were taken 6 to 8 inches below the nose during inspiration, and contain 0.7 per cent. of expired air. At $D$ the samples were taken 12 to 15 inches below the nose 
during inspiration, and the contamination amounts to only 0.1 per cent. of expired air. These tests were made in the same room as the above, when there was a measured air-supply in excess of 15,000 cubic feet per hour entering through an open transom. The temperature was $66 \mathrm{~F}$.

The conditions noted in Figures 2 and 3 are fundamental to our investigation. The contamination may be traced further; it tends to disappear rapidly, both in the time and space relation. The general facts are not particularly new or strange. They may be roughly determined by any one who will watch the course of smoke blown through the nostrils.

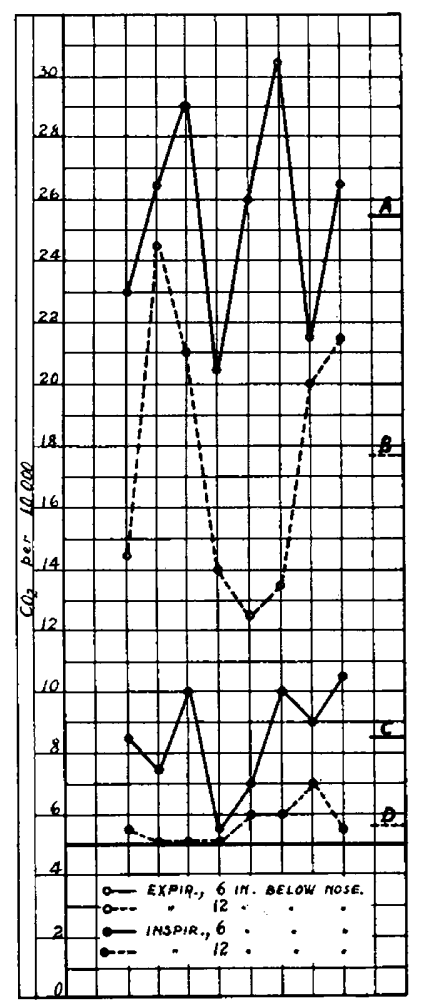

Fig. 3.- Exps. 8 and 9). Showing contamination of the air 6 to 8 inches and 12 to 15 inches below the nose during expiration $(A$ and $B$ ), and at the same places during inspiration $(C$ and $D)$.

\section{THE EFFECT OF TEMPERATURE}

It has been sometimes stated before scientific societies that when the surrounding air is cool-- below $60 \mathrm{~F}$. or thereabouts - the expired air will rise out of the breathing zone on account of its lower specific gravity, and reinspiration will not take place. The results shown in the last rhart would seem to cast a loubt on the theoretical correctness of this 
view. Those making the statement have failed to consider the downward propulsion of the expired air from the nares, that it takes on a coneshaped expansion, a part of which lies quite close to the body, and that convection currents tend to carry this part upward over the face. Inspiration succeeds expiration almost immediately; any upward current would therefore have to be very rapid in order to carry this air away before the latter process begins. Convection currents caused by the heat of the body, instead of being rapid, are just the opposite.

That reinspiration undoubtedly does take place at temperatures much below $60 \mathrm{~F}$. will be seen from the two series of observations illustrated in Figure 4. That at the left was made in a large room of 16,000 cubic feet, with windows on three sides. It had a temperature of $50 \mathrm{~F}$., and

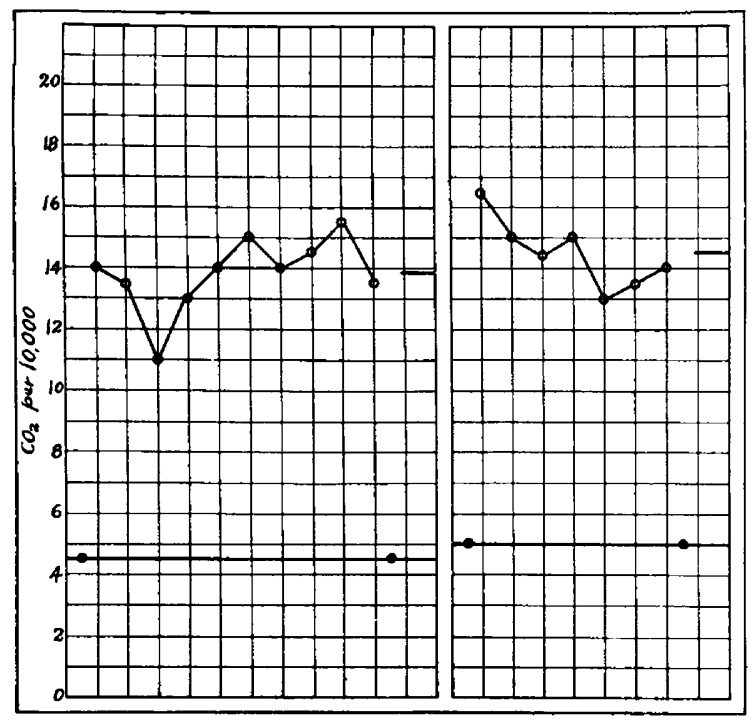

Fig. 4.-(Exps. 24 and 27.) Showing the inspired air while standing in a room of 16,000 cubic feet at $50 \mathrm{~F}$. (at the left), and in a room of 1.500 cubic feet at $43 \mathrm{~F}$. (at the right).

the reinspiration averaged 2.1 per cent. That at the right was made in a small room of 1,500 cubic feet. The temperature was $43 \mathrm{~F}$. and the reinspiration also averaged 2.1 per cent.

If a low temperature has any effect it tends to increase reinspiration. Within certain limits I believe that it does this, though I am not prepared to show that it has any constantly appreciable effect. Figure 5 shows an attempt to make the comparison in a cold and in a warm air with otherwise uniform conditions. The experiment was carried out in a small bedroom of some 1,200 cubic feet capacity. The windows and doors were closed. All samples were taken while standing perfectly free, 
about the middle of the room. Each series runs through about half an hour's time. For that shown on the left the temperature was $34 \mathrm{~F}$. and the reinspiration amounts to 2.3 per cent. For that shown at the right the temperature was $70 \mathrm{~F}$. and the reinspiration amounts to 2 per cent. The former was taken late at night, the latter late the next morning. The changing $\mathrm{CO}_{2}$ in the general air of the room may be accounted for by the presence of the experimenter; and the difference in the $\mathrm{CO}_{2}$ of this air for the two series by pure air entering from without through the window crevices in the first, whereas in the last the currents were reversed and air was entering from the hallway after being already slightly contaminated. In each instance the room had been unoccupied before the beginning of the experiment.

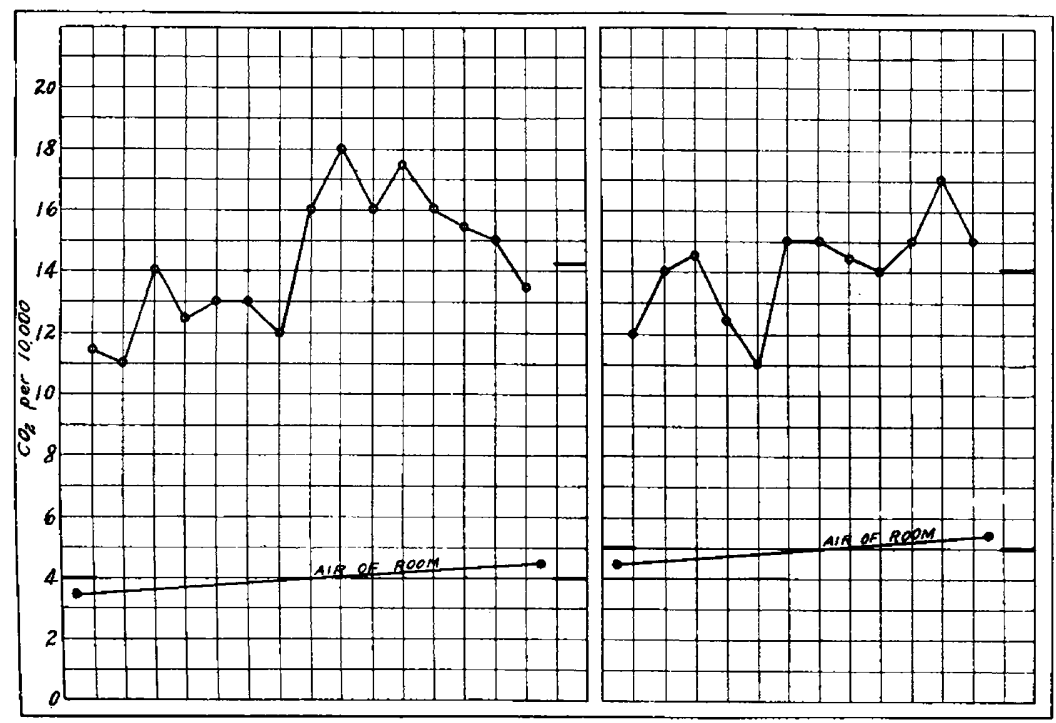

Fig. 5.-(Kxp. 23). Showing the inspired air in a room with a temperature of $34 \mathrm{~F}$, (on the left), and in the same room with a temperature of $70 \mathrm{~F}$. (on the right), all other conditions remaining essentially the same.

\section{THE EFFECT OF VENTILATION CURRENTS}

It is reasonable to suppose that the greater the volume of air supplied to a room the less evident will be the phenomenon of reinspiration, because of the greater motion imparted to the air of the confined space. In a measure, this supposition is correct; but it does not follow that a large air-supply to a room will entirely prevent the immediate reinspiration of expired air by the occupants. 'There are a number of factors determining the limits of air-supply which will be found of too much importance to permit of a sufficient ventilation to control the matter entirely, or even to limit it in a very marked degree. 
The results of an experiment carried out in a small bedroom of about 1,000 cubic feet, and also at the low temperature of $43 \mathrm{~F}$., are illustrated in Figure 6. The room has one window and two doors. A strong wind was blowing without. The series shown at the left was taken with closed doors and window; in that at the right the window was raised so as to give one square foot of opening, and admitted air at the rate of 16,500 cubic feet per hour - enough to accomplish in excess of sixteen complete changes each hour. In the first, the reinspiration amounts to 1.9 per cent.; in the second it fell to only 1.4 per cent. Most of the samples of air were taken while standing, a few while sitting on the edge of the bed, which was about 6 feet from the window. It is probable that there is a slight error in determining the $\mathrm{CO}_{2}$ in the air of the room for the

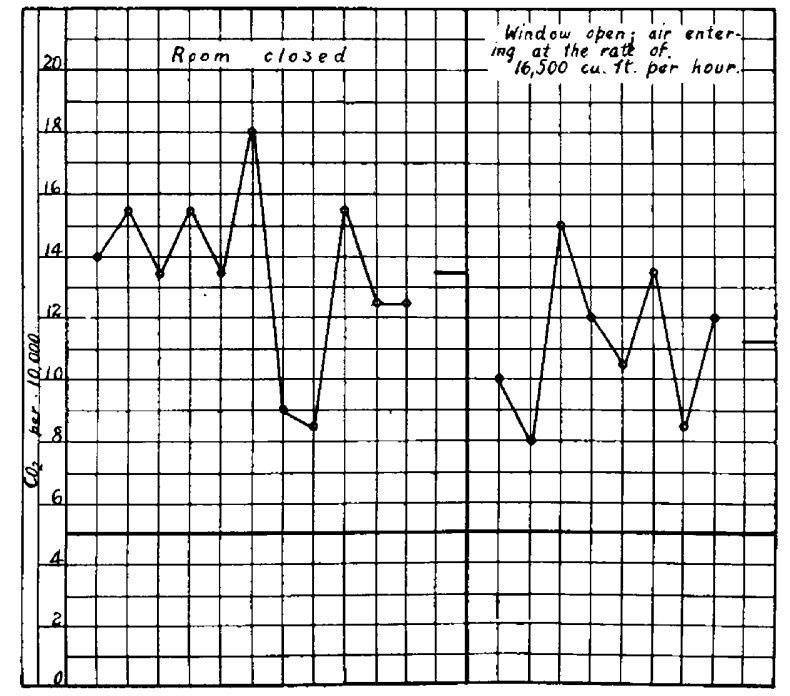

Fig. 6.-(Exp. 4). Showing the inspired air in a room with a small air supply and in the same room with a large air supply.

second series, and that the base line should be dropped to 4 , which would make the difference between the two groups still less striking.

The difference produced by a large air-supply, or even by a moderate one, is, in many instances, more marked than in the above experiment. When one sits or stands directly between the inlet and the outlet, and the air-supply is large, the proportion of the breath which is reinspired may drop to nearly nothing. Two experiments made under these conditions in a room of 3,000 cubic feet with a temperature of $70 \mathrm{~F}$. are shown in Figure 7. In each instance the air-supply came in through a door from the adjacent hallway and left through a window diagonally opposite. It was measured at the exit. The samples of inspired air were taken while 
sitting directly in the line between door and window, and twice as far from the former as from the latter. In the curve marked $A$ the air-supply was at the rate of 28,000 cubic feet per hour; in the curve marked $B$ it was at the rate of 63,000 cubic feet per hour. The average reinspiration is 1.1 per cent. for $A$, and 0.6 per cent. for $B$. The base line representing the $\mathrm{CO}_{2}$ in the general air of the room was not the same in these two instances, but in the chart the curves are adjusted to a common base of 5 , in order to make a clear and accurate comparison.

On another occasion the same room was found to be receiving 324,000 cubic feet of air per hour through the open door. This was leaving through the open window as before. It was possible in this instance to measure by the anemometer the air current in the position occupied for

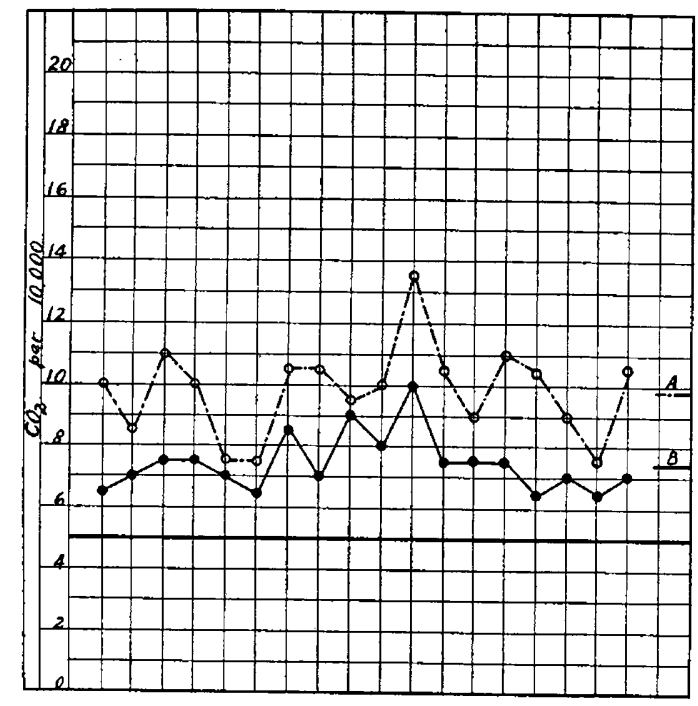

Fig. 7.-(Exps. 18 and 21). Showing the inspired air while sitting directly between inlet and outlet of a room of 3,000 cubic feet, ventilated by 28,000 cubic feet of air per hour $(A)$, and by 63,000 cubic feet per hour $(B)$.

the tests. This was found to be about 120 feet per minute. The negative results of the reinspiration test are shown in the curve marked $A$ in Figure 8. But on moving about 6 feet out of the direct line between the door and the window the result was changed to a reinspiration of 0.6 per cent., as can be seen in the curve marked $B$ in the same chart. In this latter position the anemometer moved irregularly, sometimes forward nnd sometimes backward. The amount of air being supplied during this experiment is of course much larger than can ordinarily be used to rentilate a room of this size, whatever the method of ventilation employed. 


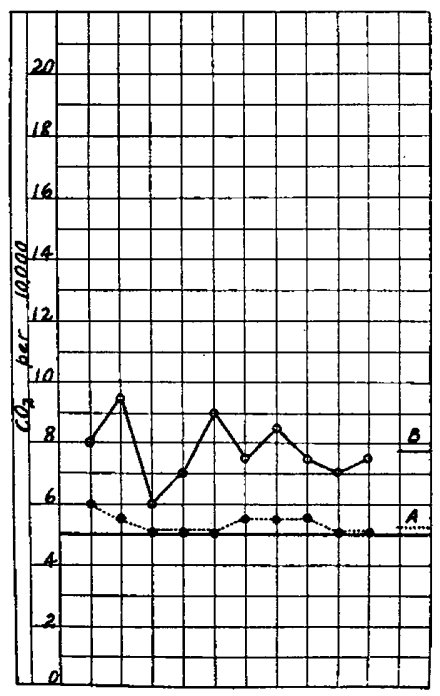

Fig. 8.-(Exper. 20). Showing the absence of reinspiration while sitting directly between inlet and outlet of a room of 3,000 cubic feet, ventilated by 324,000 cubic feet of air per hour $(A)$, and its presence when sitting 6 feet out of the direct line $(B)$.

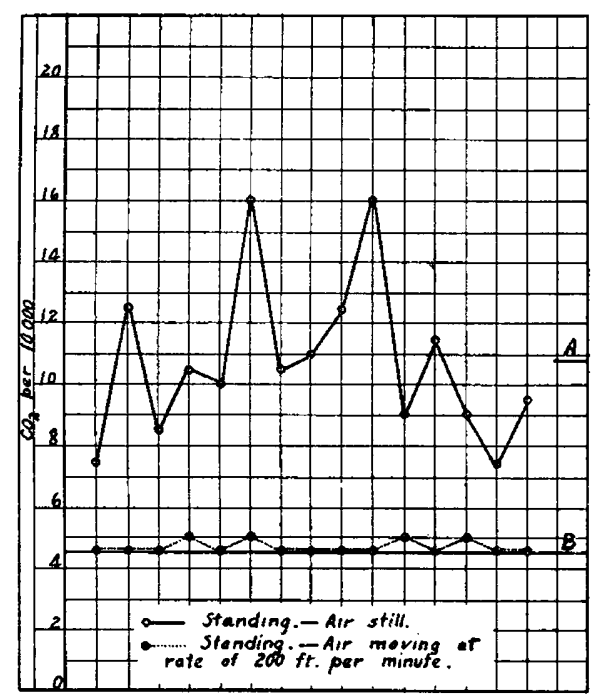

Fig. 9.-(Exper. 12). Showing that there is no reinspiration when facing a breeze of 200 feet per minute $(B)$, contrasted with 1.4 per cent. reinspiration when the air is relatively still $(A)$. 
By the employment of properly directed artificial currents it is quite easy to prevent reinspiration entirely. This may be readily accomplished by means of an electric fan, provided the face is free to receive the breeze. If there is obstruction to the free flow of the current of air, the results may be quite different, as will be demonstrated later. Figure 9 shows very well what happens in a fan current moving at the rate of 200 feet per minute when there is no obstruction (curve $B$ ), and also what happens in the same place when the fan is shut off (curve $A$ ). Such an experiment also serves well as a control of the technic, which was identical for the two series. The room in which it was made contains 2,500 cubic feet and had a temperature of $68 \mathrm{~F}$.

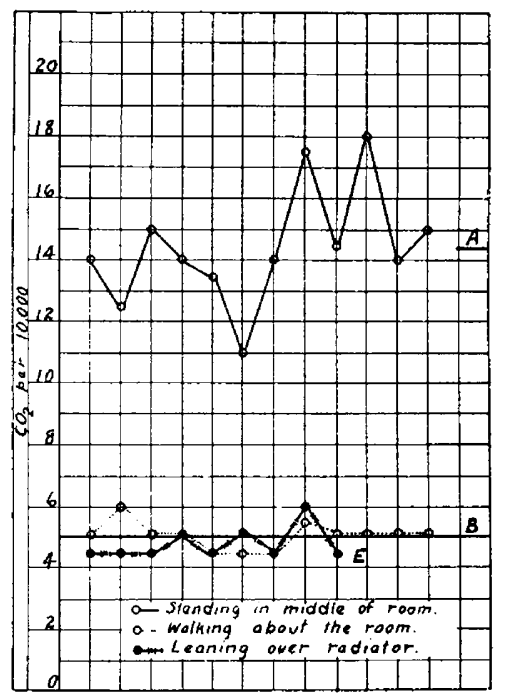

Fig. 10.-(Exp. 10). Showing no reinspiration when walking about the room $(B)$, or when leaning over a radiator $(E)$, contrasted with 2.1 per cent. when standing still $(A)$.

The same result may be obtained by walking about the room, thus creating one's own current of some 200 to 300 feet per minute, and leaving behind at each step the expired breath. The walking may be confined to a very small circle without any change in the results. It is equally effective to stand with the head above a radiator, which, when well heated, will cause an upward convection current of some 200 feet per minute. Figure 10 illustrates these statements very well, and shows that 2.1 per cent. of the expired air was rebreathed when standing still. This experiment was made in the same room as the foregoing, with closed windows and a temperature of $63 \mathrm{~F}$. 
Results confirming those above noted are shown in Figure 11. When this experiment was made, the room was receiving 28,000 cubic feet of air per hour from an open window and the temperature was $66 \mathrm{~F}$. On account of the large inflow of cool air, the air near the floor contained only $4 \mathrm{CO}_{2}$ per 10,000 , while it had 4.5 at a height of 5 feet above the floor. The same difference is detected in curves $B$ and $C$, the former of which represents samples of the inspired air taken in the upward current over the radiator, and the latter those taken while walking about the room. When standing quietly in the middle of the room the reinspiration was 1.2 per cent., as shown in the curve $A$.

In connection with the avoidance of reinspiration by induced air currents, the interesting observation has been made that when the back

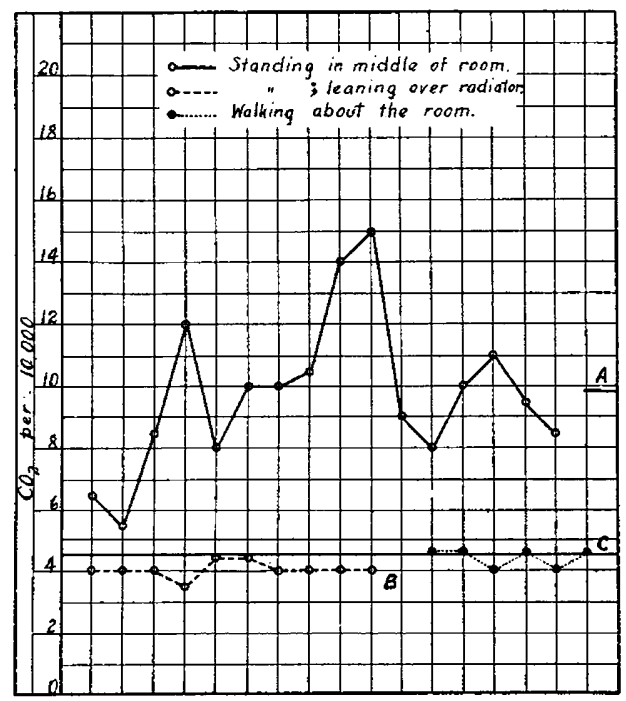

Fig. 11.-(Exp. 6). Showing no reinspiration when walking about the room $(C)$, or when leaning over a radiator $(B)$, contrasted with 1.2 per cent. when standing still $(A)$. The room was receiving 28,000 cubic feet of air per hour from an open window.

is turned to the breeze a little of the expired air is often reinhaled in spite of the current. This is interpreted to mean that the eddies formed in front of the face prevent an immediate removal of the expired air. Two experiments made while standing in a narrow hallway with a very regular flow of air, and which illustrate this, are shown in Figure 12. In that shown at the left the current was just perceptible, presumably about 150 feet per minute; in that at the right the current was 300 feet per minute. The samples in each series were taken alternately, one while facing toward, then one while facing away from, the air current. 


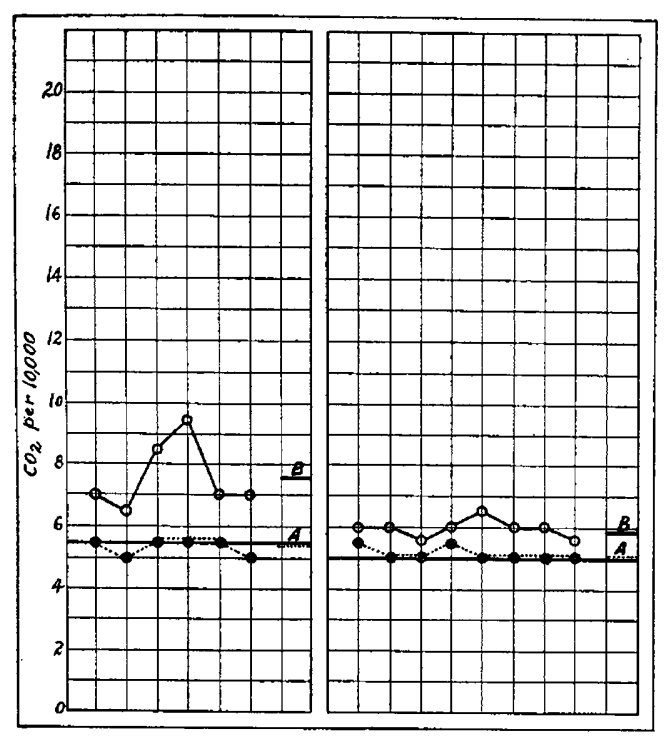

Fig. 12.-(Exps. 3 and 19). Showing that air currents of small velocity do not entirely prevent reinspiration when directed from behind $(B)$, but do when directed from the front $(A)$.

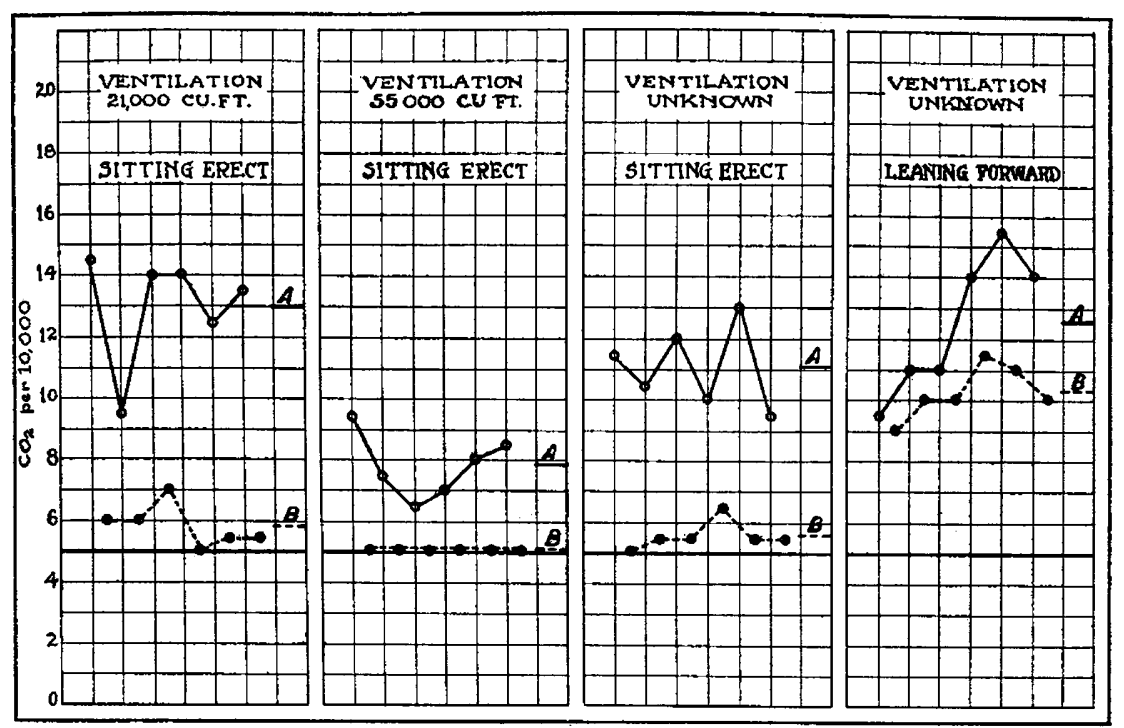

Fig. 13.-(Exper. 2). Showing that there is practically no reinspiration with mouth breathing unless the expired current is directed downward, as in $B$ at the extreme right. $A$, nasal breathing; $B$, mouth breathing. 


\section{THE EFFECT OF MOUTH BREATHING}

If one sits erect and breathes through the open mouth the expired air is thrown directly forward; only the tip of the cone-shaped expansion lies next to the face, and a very slight motion will carry it out of the zone from which the inspired air is taken. Even the slow convection currents are usually sufficient to cause this slight motion within the necessary time limits. This results in there being practically no reinspiration with mouth breathing, unless there is such a change of position of the head as to throw the expired current downward, or unless some obstruction is brought in the way of its forward motion. The facts are well illustrated in Figure 13. This experiment was made in a room of 3,000 cubic feet with a temperature of $70 \mathrm{~F}$. The ventilating air came

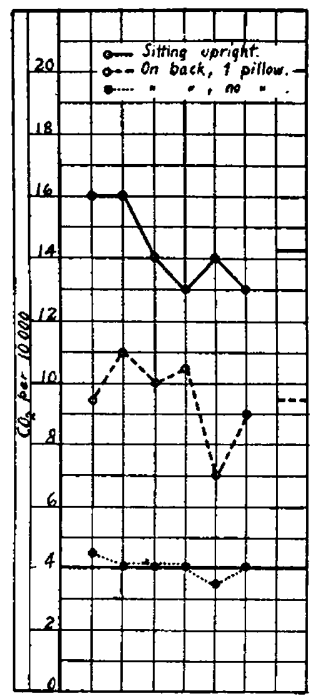

Fig. 14.-(Exp. 16). Showing the effect of position on reinspiration.

from a hallway and had constantly $5 \mathrm{CO}_{2}$ per 10,000 . Nasal breathing is represented by the curves marked $A$, and mouth breathing by those marked $B$. The position of the body in the fourth group was that which is usually assumed when seated for writing at a table. The mouth and nasal samples were taken alternately in each of the four groups. Abundant confirmation of these results were noted in other experiments.

\section{THE EFFECT OF POSITION}

Every change of position of the head affects the line in which the expired air is directed. In the normal sitting or standing position (with nasal breathing), as has been previously stated, it is thrown downward, close to the body, and there are more or less constant upward 
convection currents which tend to bring it back to the face. If the head is thrown well back the air is thrown away from the body, somewhat as it is in breathing through the open mouth, and reinspiration is lessened or prevented entirely.

The effect of such changes can be best studied by assuming the recumbent position and lowering or raising the head. Figure 14 shows three short series of observations made under these conditions in a bedroom of 1,500 cubic feet with a temperature of $64 \mathrm{~F}$. While sitting on the bed, propped upright against the headboard, the reinspiration was

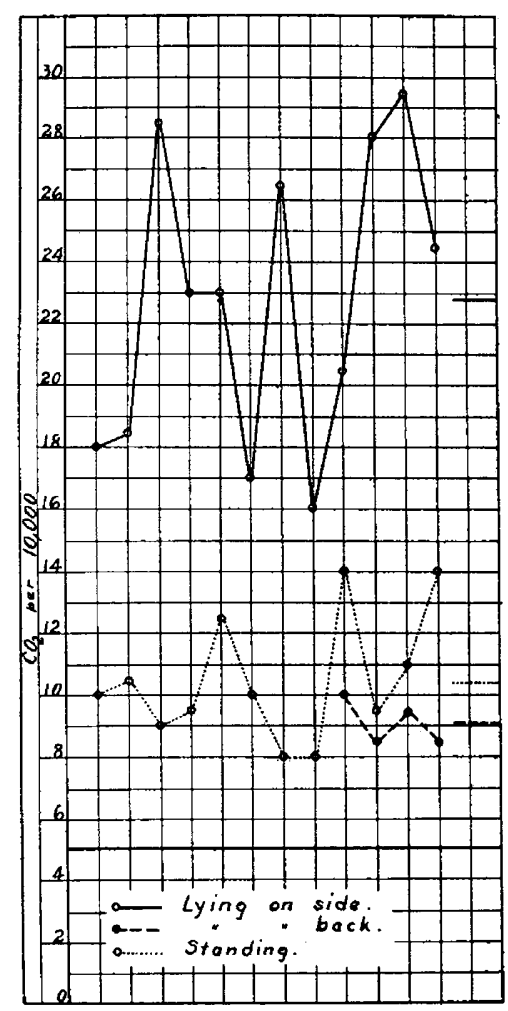

Fig. 15.-(Exp. 5). Showing the effect of position on reinspiration.

2.3 per cent.; lying down with a pillow tilting the head forward it was 1.3 per cent.; when the pillow was removed and the head thrown far back there was none at all.

It is well known that gases tend to adhere to surfaces with which they come in contact. When one lies with the side of the face on a pillow, the expired air is directed against its surface, and this adhesion will delay its removal from the immediate neighborhood of the face. Furthermore, there is the formation of pockets and dead spaces in the angles which are 
not easily acted on by convection currents. The softer the pillow, and the more one's head sinks into it, the greater will be the retention. The result of lying in the position indicated is that relatively large amounts of the expired air are reinhaled. This is illustrated by the experiment shown in Figure 15, made in the same room as the preceding, with a temperature of $60 \mathrm{~F}$. While standing by the edge of the bed the reinspiration was 1.2 per cent.; lying with the side of the face on the pillow it was 4 per cent.; lying on the back with a pillow under the head it was 1 per cent. In this, as in the preceding and in all other similar experiments, there

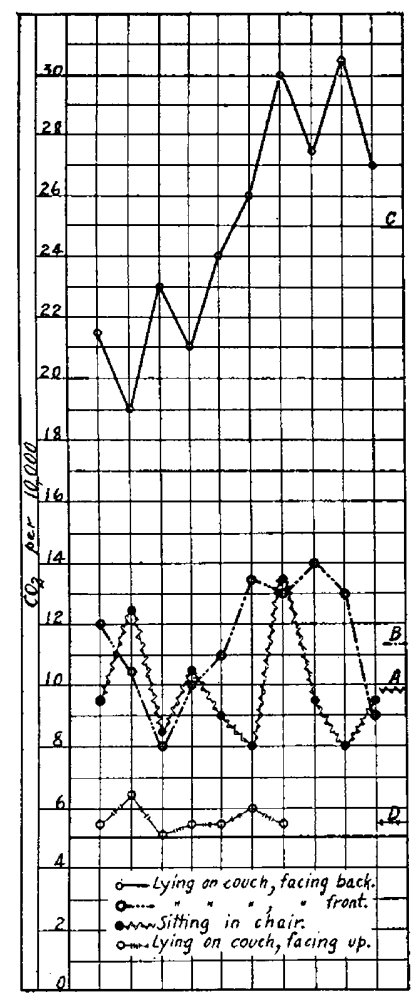

Fig. 16.-(Exp. 11). Showing the effect of position on reinspiration.

was no obstruction by blankets or other covering. The only effect of such obstructions would be considerably to increase the amount of air reinspired.

The effects of position are again illustrated by the experiment shown in Figure 16, which was carried out in a large and well-ventilated sitting room, with an open fire-place and a vigorous fire. The temperature rose while the tests were being made from $64 \mathrm{~F}$. to $72 \mathrm{~F}$. When sitting in a chair some 8 or 10 feet from the fire the reinspiration was 1.1 per cent. 
$(A)$; lying on a couch, with the face toward the edge and a little removed from it, the reinspiration was 1.4 per cent. $(B)$; with the face toward the high back of the couch, and some 8 or 10 inches from it, there was 4.4 per cent. reinspiration $(C)$; while lying on the back, with a very miniature pillow, there was practically none $(D)$.

As might be readily inferred from the results of the foregoing experiments, it was found that ventilating currents have less effect on reinspiration in the lateral recumbent position than when the head is free. The adhesion of the expired air and the mechanical obstruction about the face

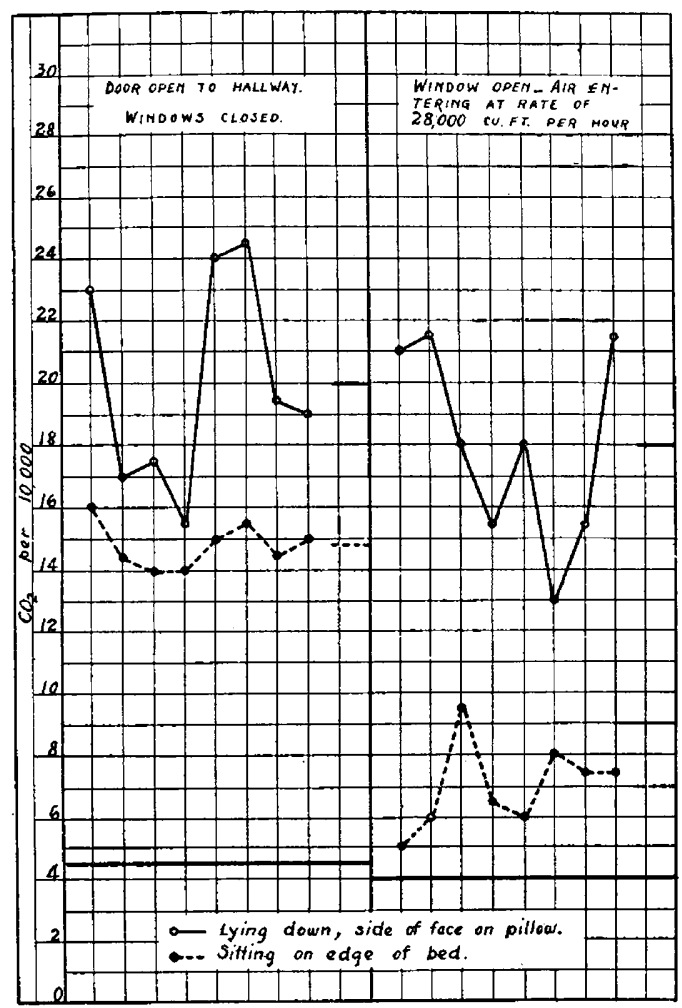

Fig. 17.-(Exp. 7). Showing effect of position and changing ventilation on reinspiration.

prevent the ready action of such currents in bringing about displacement. The condition is illustrated by the experiment shown in Figure 17. This was made in a bedroom of about 1,500 cubic feet, where the temperature was $50 \mathrm{~F}$. With closed windows the reinspiration was 2.3 per cent. and 3.4 per cent. for the upright and recumbent positions, respectively; with an open window admitting air at the rate of 28,000 cubic feet per hour they were 0.7 and 3.1 per cent., respectively. 
The difficulty of dislodging the expired air even by artificially produced direct currents, when one breathes over the surface of a pillow, is further illustrated in Figure 18. This experiment was made while lying on the side as in the preceding. The temperature was $70 \mathrm{~F}$. The current of air was from an electric fan placed beyond the feet and nearly in line with the body, but a little behind. It was about 12 feet from the head and 2 feet above the bed. The current was measured just above the pillow - practically in the position assumed by the head when lying there. When the air was not disturbed the reinspiration was 3.6 per

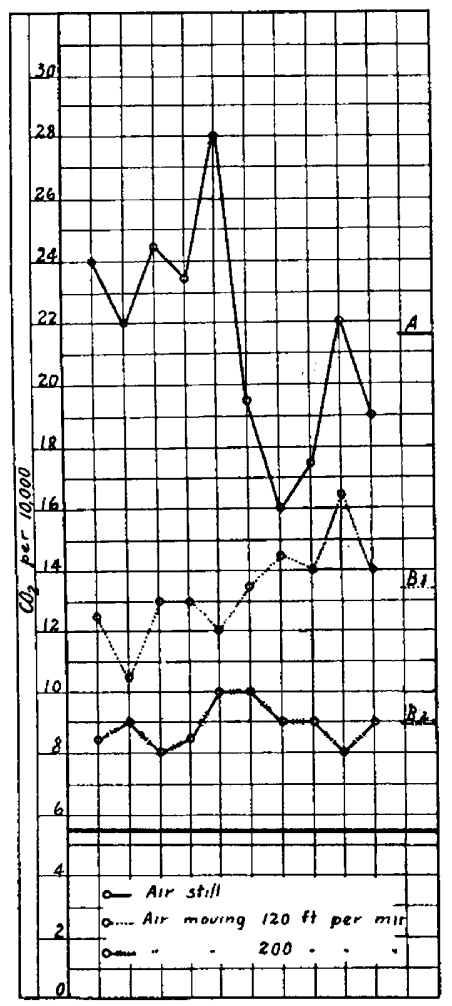

Fig. 18.-(Exp. 13). Showing the effect of air currents on reinspiration while lying with the side of the face on a pillow.

cent. $(A)$; with a current of 120 feet per minute it was 1.8 per cent. $\left(B_{1}\right)$, and with a current of 200 feet per minute it was 0.7 per cent. $\left(B_{2}\right)$. With the head free and facing the breeze either of these currents is sufficient to prevent reinspiration entirely.

An air current strong enough to be felt as a breeze may still fail to remove the expired air under the above conditions, even when it flows directly at the face. This is illustrated by Figure 19. The observations 
were made in the same place as the above. The temperature was $60 \mathrm{~F}$. When the air was not artificially disturbed there was 2.8 per cent. reinspiration $(A)$; with a fan current of 150 feet directed from behınd the body there was 2.1 per cent. $(B)$; and with the same current directed from in front there was still 1.1 per cent. $(C)$. The breeze was quite perceptible on the face.

THE EFFECT OF INCREASING AND DECREASING $\mathrm{CO}_{2}$

The degree of contamination in the surrounding air has practically no effect on the amount of immediate reinspiration. Any increase or decrease of the $\mathrm{CO}_{2}$ in the general air of a room is accompanied by corresponding changes in the $\mathrm{CO}_{2}$ of the inspired air. The gap between

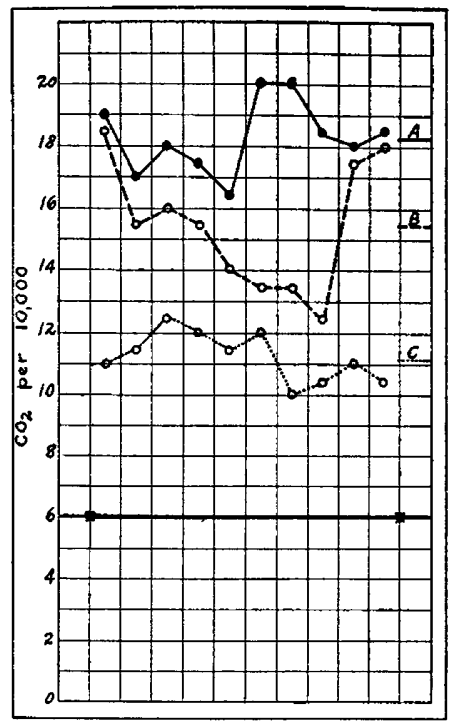

Fig. 19.-(Exp. 26). Showing the effect of air currents from different directions on reinspiration while lying on side. Air still at $A$; a current of 150 feet per minute from behind at $B$, and from in front at $C$.

the two remains about the same wherever they lie in the scale. It is understood, of course, that these statements apply only when other conditions, such as temperature and air currents, are unaltered. After Lehmann ${ }^{1}$ had highly contaminated the air of his laboratory by burning gas, he found about the same difference in $\mathrm{CO}_{2}$ content between this air and the inspired air that was found on other occasions when the laboratory air was relatively pure.

In order to test the matter in another way, I shut myself in an otherwise empty clothes closet of 175 cubic feet, which could be rapidly contaminated by my own expiration, and made stimultaneous observations 
of the air of the room and my inspired air at five-minute intervals. After ten samples of each had been collected the door was opened and the place thoroughly fanned for ten minutes to renew the air; then six more samples of each were taken at similar intervals, the door being open, the room vacated, and the air agitated during the intervals in order to prevent any reaccumulation of $\mathrm{CO}_{2}$, but closed while the samples were being taken. 'The temperature was 78 to $80 \mathrm{~F}$.

During the first period of the experiment the $\mathrm{CO}_{2}$ of the air of the room rose in a very regular curve from 6.5 to 16.5 per 10,000 , and the

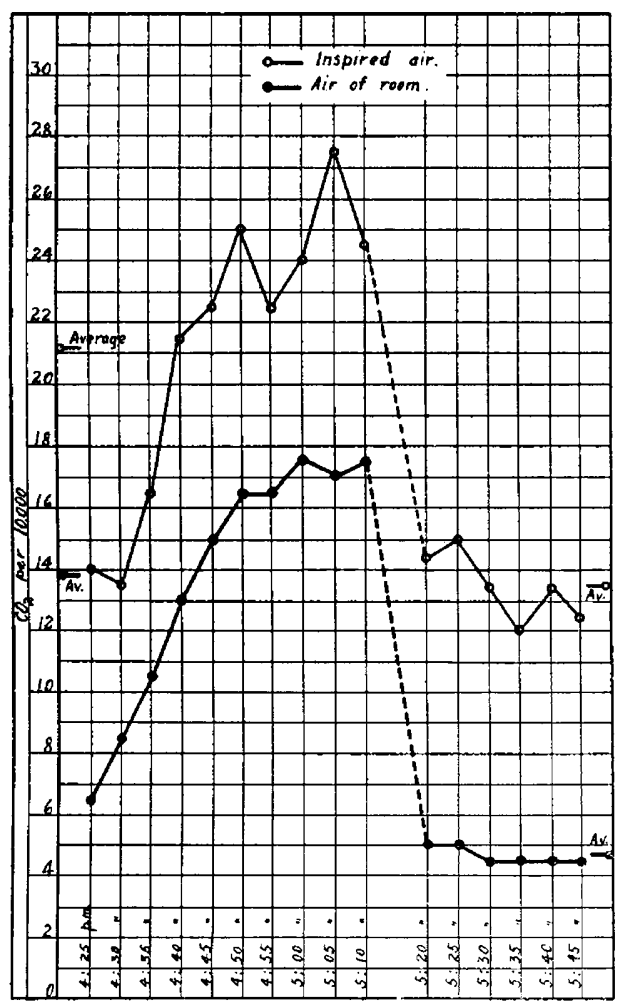

Fig. 20.- (Exp. 15). Showing that changing the $\mathrm{CO}_{2}$ in the surrounding air has practically no effect on the amount of reinspiration.

$\mathrm{CO}_{2}$ of the inspired air rose in an irregular but corresponding curve a like amount. During the fanning-out process the $\mathrm{CO}_{2}$ of the air of the room fell to 5 per 10,000 , near which it remained during the subsequent tests. The $\mathrm{CO}_{2}$ of the inspired air also dropped back to about the starting point and remained there. These results are shown in Figure 20. During the first period the average reinspiration was 1.6 per cent.; during the second period it was 1.9 per cent. 
The results of the first part of this experiment were verified on another occasion under similar general conditions, and in addition to the above, a sample of the air inhaled through the open mouth was taken at each five-minute period. The $\mathrm{CO}_{2}$ of the air of the room rose from 5 to 14 per 10,000, and averaged 11 per 10,000 . The $\mathrm{CO}_{2}$ of the inspired air with nasal breathing likewise rose in an irregular curve and averaged 18.3 per 10,000 , the difference $(7.3$ per 10,000$)$ being equivalent to a reinspiration of 1.6 per cent. The $\mathrm{CO}_{2}$ of the inspired air with mouth breathing followed very closely that of the air of the room; they averaged within a small fraction of each other, thus showing practically no reinspiration while breathing through the open mouth, as has been previously stated.

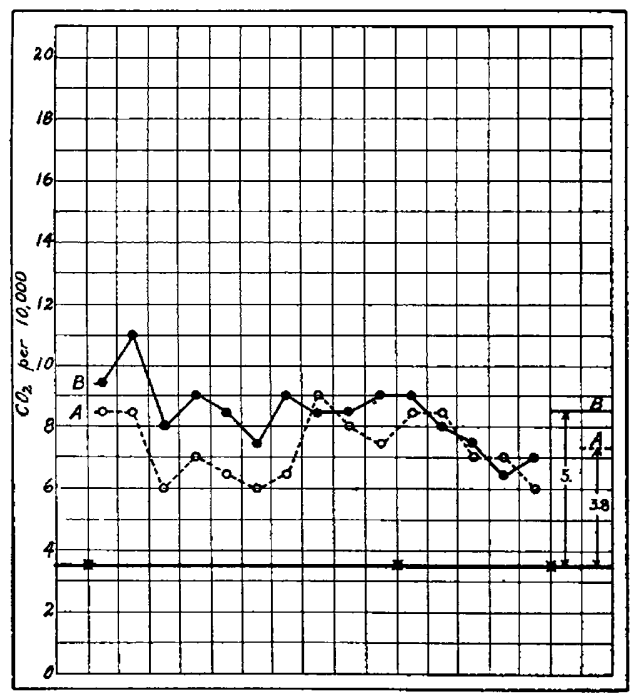

Fig. 21.-(Exp. 28). Showing reinspiration in a sleeping-porch when sitting near the center $(A)$, and while lying on a bed near an open side $(B)$.

\section{THE SLEEPING-PORCH AND THE OPEN AIR}

From the experiments recorded it is evident that very slight interference with the free movement of air currents about the face is sufficient to prevent the immediate removal of the expired air and to allow contamination of the air we breathe. It was believed that such interference might easily occur in the ordinary sleeping-porch, which is usually built with two open sides, or, sometimes, even in the open air. Investigation of the inspired air under these circumstances was made, and the results found to be in harmony with those previously obtained. One does not necessarily breathe pure air because he is out of doors; he is not at all likely to do so under the ordinary conditions of sleeping in tents, tenthouses, or half-open porches, such as are used for therapeutic or hygienic purposes. 
An experiment carried out in a sleeping-porch $15 \times 13 \times 8.5$ feet is shown in Figure 21. The porch has open sides to the south and east, covered by wire screens of about 12 meshes to the inch. The temperature was $70 \mathrm{~F}$., and there was a breeze of 400 to 500 feet per minute in the outside air, varying in direction between south and southwest. The air of the porch, and outside of it, contained $3.5 \mathrm{CO}_{2}$ per 10,000, as shown ly three successive determinations made in duplicate and indicated on the base line in the chart. This porch contained two beds, one of which stood near the center and opposite a door in the north wall, and one of which was close to the open east side. Two series of tests were made: one while sitting on the edge of the center bed $(A)$, and one while lying on the other bed with the face about 2 feet from the screen $(B)$. The reinspiration was 0.8 per cent., and 1.1 per cent. for the two series, respectively.

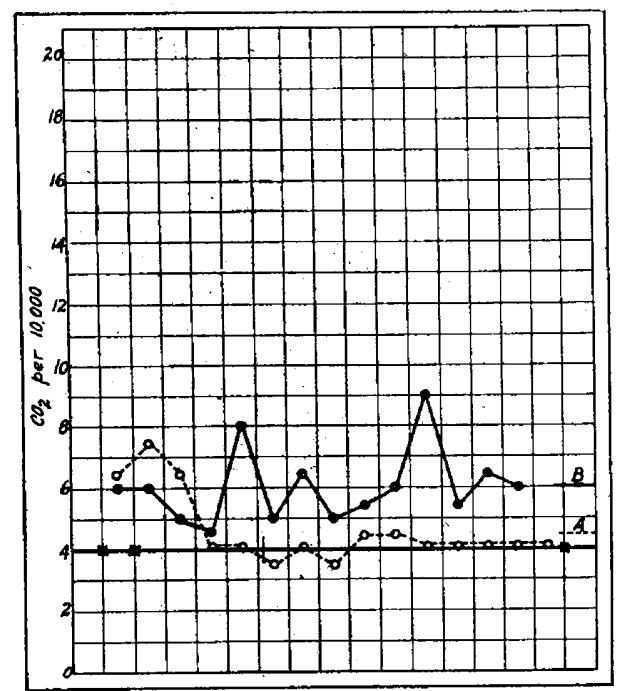

Fig. 22.-(Exp. 29). Showing the inspired air when out of doors. A, standing free; $B$, on an open porch.

Lehmann ${ }^{1}$ made four observations in the outside air and found the difference between the $\mathrm{CO}_{2}$ of the inspired air and of the surrounding air to be $0.6,0.3,0.8$ and 0.0 per 10,000 . The difference is so small as to indicate practically no reinspiration. I have made similar findings. The outside air is rarely still, and it moves in great masses. If there is no obstruction the expired air is quickly removed from the breathing zone. If one stands perfectly free there will be no reinspiration, except occasionally on very still days. But it is only necessary to step behind an obstruction of some sort to break up the progressive mass movement of the atmosphere, and the phenomenon begins again. These two conditions are shown in Figure 22. There was a light breeze blowing and the temperature was $70 \mathrm{~F}$. The curve $A$ shows a series of tests while 
standing well away from any obstruction. Another person was standing only a few feet distant and on the windward side. It is possible that his expired air accounts for the excess of $\mathrm{CO}_{2}$ in the first three samples of this series. The curve $B$ shows a series while seated on an open porch built against the side of the house and opposite to the direction of the wind. The reinspiration is not great, but it is present. The inspired air is not pure, and the experiment serves to show how necessary it is that the air currents be free and unobstructed in order that uncontaminated air may enter the nostrils.

The experiments illustrated and referred to in the preceding represent only such conditions as are likely to be met with in daily life. With the single exception of the closet, the rooms utilized were well ventilated. Many times the air-supply was excessive. The attempt has been made to determine what kind of air is breathed under ordinary and good conditions, rather than what may be breathed under exceptionally bad conditions. It may be fairly concluded that when one lives indoors and remains quiet he will immediately rebreathe from 1 to 2 per cent. of his own expired air. When he goes to bed it will be more - from 1 or 2 per cent. to 4 or 5 per cent., depending on the position in which he lies. In some of the positions assumed by people sleeping it may even be as high as 8 or 10 per cent.; and I have once found it 18 per cent. in a single test, which did not necessitate a position by any means improbable. Nor does sleeping in the open insure pure air for breathing. The same influences here produce the same relative results that they do inside. When one buries his head between pillow and bed-clothes for the sake of warmth, reinspiration is inevitable, and it is not necessarily small in amount.

\section{THE SIGNIFICANCE OF REINSPIRATION}

The phenomenon of reinspiration has been recorded with rather less detail than was observed in the experiments, but with enough to show that it must be a very common occurrence. In order to understand its significance it is necessary to consider certain phases of the physiology of respiration.

Haldane and Priestly ${ }^{4}$ have shown that the regulation of breathing is dependent on the concentration of carbon dioxid in the air-cells of the lungs. By the proportion of $\mathrm{CO}_{2}$ in the air-cells the concentration of this gas in the arterial blood is determined, and the nerve cells controlling the respiratory movements are stimulated by the carbonic acid in the blood supplied to them. Hough ${ }^{5}$ confirmed these findings. He concludes, from

4. Haldane and Priestly: The Regulation of the Lung Ventilation, Jour. Physiol., 1905, xxxii, 225.

5. Hough: Variations in the Response of Healthy Men to the Dyspneic Conditions Produced by Breathing a Confined Volume of Air, Am. Jour. Physiol., 1911, xxviii, 369 . 
experimental evidence, that "the increase of pulmonary ventilation is entirely the result of increase of the $\mathrm{CO}_{2}$ tension in the blood flowing through the respiratory center"; and Henderson" believes that "the capnicity of the body [the concentration of $\mathrm{CO}_{2}$ in the blood] is automatically maintained with a precision equalling that exhibited in the regulation of body temperature."

The carbon dioxid which is being constantly formed in the body is carried to the lungs by the venous blood. It escapes from the blood into the air-cells of the lungs, and its escape is impeded or accelerated according to the resistance it meets in them. This resistance depends on the proportion of $\mathrm{CO}_{2}$ in the alveolar air, since the tension of this gas in the blood can fall only as low as it is on the other side of the membrane separating the blood-stream from the air-cell. The arterial blood leaves the lungs with essentially the same pressure of $\mathrm{CO}_{2}$ that is found in the alveolar air. It is in this way that the alveolar $\mathrm{CO}_{2}$ regulates the $\mathrm{CO}_{2}$ tension in the blood, and so controls the respiratory movemients.

Each person's breathing is so regulated as to maintain the percentage of $\mathrm{CO}_{2}$ in the alveolar air at about 5 per cent. of an atmosphere. If the pressure falls below this, respiration is lessened or stopped until the loss is regained; if it goes above 5 per cent., the respiration is increased until the normal is restored. With light muscular work the $\mathrm{CO}_{2}$ formed in the body will be doubled or trebled, and the breathing will be increased in like proportion so as to remove the $\mathrm{CO}_{2}$ from the air-cells just fast enough to maintain the alveolar tension at the normal 5 per cent., but not lower. Douglas and Haldane found that from lying in bed to walking five miles per hour the $\mathrm{CO}_{2}$ output was increased twelve times, and that the alveolar ventilation was likewise increased twelve times, so that the percentage of $\mathrm{CO}_{2}$ in the alveolar air remained practically constant. Henderson ${ }^{6}$ found no material change in the composition of the alveolar air on going from rest to strenuous exercise; the increased production of $\mathrm{CO}_{2}$ was perfectly compensated for by increased breathing.

Haldane and Priestly found not only that the percentage of $\mathrm{CO}_{2}$ in the alveolar air remains constant under all degrees of exertion, but that its absolute partial pressure is unaltered when the general pressure is reduced to two-thirds of an atmosphere. 'That the same rule holds good in the increased pressure of caissons having up to 6 atmospheres has been shown by Hill. ${ }^{3}$ In his experiments he found the alveolar air to contain 5.4 per cent. of $\mathrm{CO}_{2}$ at 1 atmosphere, and it gradually fell, with increasing pressure, to 0.9 per cent. at 6 atmospheres, the percentage

6. Henderson and Russell: A Simple Method for Determining the Carbon Dioxid Content of the Alveolar Air, Am. Jour. Physiol., 1912, xxix, 436.

7. Douglas and Haldane: The Dead Space of the Respiratory Passages, Jour. Physiol., 1912, Abst. in Brit. Med. Jour., Nov. 16, 1912, p. 1411.

8. Hill, Leonard: Caisson Sickness. Edward Arnold, London, 1912, p. 47. 
changing in an inverse ratio to the increase of external pressure, so that the absolute tension of $\mathrm{CO}_{2}$ in the alveolar air always remained at about 5 per cent. of the pressure of one atmosphere.

Haldane and Poulton ${ }^{9}$ have shown that if the $\mathrm{CO}_{2}$ is first removed from the lungs by rapid breathing, apnea may coexist with actual want of oxygen, and that breathing does not begin again until the alveolar $\mathrm{CO}_{2}$ has returned to the normal. ${ }^{10}$ Alveolar air normally contains about 16 per cent. of oxygen, and the red blood-cells leave the lungs practically saturated with it. The amount taken up on their next trip through the lungs depends on how much they have given up to the tissues in the meantime, not on how much is available to their use. The normal 16 per cent. of oxygen in the alveolar air is automatically maintained by the action of the $\mathrm{CO}_{2}$ on the respiratory center, but on account of the chemical affinity of the hemoglobin for oxygen the blood-cells may still take practically their full capacity when it is reduced to 12 per cent. or less in the alveolar air. Thus a large excess of oxygen is constantly maintained in the air of the lungs. And while it is one of the chief functions of respiration to supply oxygen to the body, neither a surplus nor a deficiency of it, unless the alteration is extreme, have any effect on the respiratory movements. Breathing will not be lessened nor more oxygen taken up because more of it is supplied to the lungs; nor will the oxidation processes in the body be affected in any way, unless other influences are simultaneously brought into play.

With each breath we take back into the lungs the air contained in the nose and larger bronchi - the "dead-space" air. This dead-space air constitutes about one-third of the whole volume of quiet inspiration, and not less than one-tenth of deep breathing. To all intents and purposes it is expired air which is constantly reinspired. The phenomenon of reinspiration now under discussion is in effect simply a slight extension of the dead-space beyond its necessary limits. Rebreathing of the ordinary dead-space air is a normal and conservative process; it prevents pure air from entering the lungs and reducing the $\mathrm{CO}_{2}$ below the amount required for stimulating the respiratory center; it makes of breathing a regular and continuous rather than an irregular and interrupted function. Douglas and Haldane ${ }^{7}$ have recently shown that the volume of the deadspace, instead of being a fixed quantity, is automatically altered so as to give greater or less resistance to the air-flow to and from the lungs with changing exertion. They go so far as to state that rather marked variations may occur; and, while the mechanism is not fully understood, they

9. Haldane and Poulton: The Effect of Want of Oxygen on Respiration, Jour. of Physiol., 1908, xxxvii, 390.

10. Unless oxygen has fallen so low in the body that imperfect oxidation in the processes of metabolism causes the formation of abnormal acids, notably lactic, which reinforce the $\mathrm{CO}_{2}$ in the blood for action on the respiratory center. 
think the regulation is as perfect as is that of the size of the arterioles for controlling the blood-flow.

There can be no doubt that there is a large measure and a wide range of physiologic response on the part of the respiratory function to meet changing external as well as internal conditions of $\mathrm{CO}_{2}$ concentration. It has been seen that when more $\mathrm{CO}_{2}$ is formed in the body the respiration is automatically increased in like proportion, and in this way the alveolar $\mathrm{CO}_{2}$ is kept at a uniform level of 5 per cent. The same thing happens when we breathe an atmosphere containing an excess of $\mathrm{CO}_{2}$. The volume of air breathed is then increased in such a degree as, if possible, to keep the $\mathrm{CO}_{2}$ in the alveolar air normal. Haldane and Priestly found that with 2 per cent. of $\mathrm{CO}_{2}$ in the inspired air the

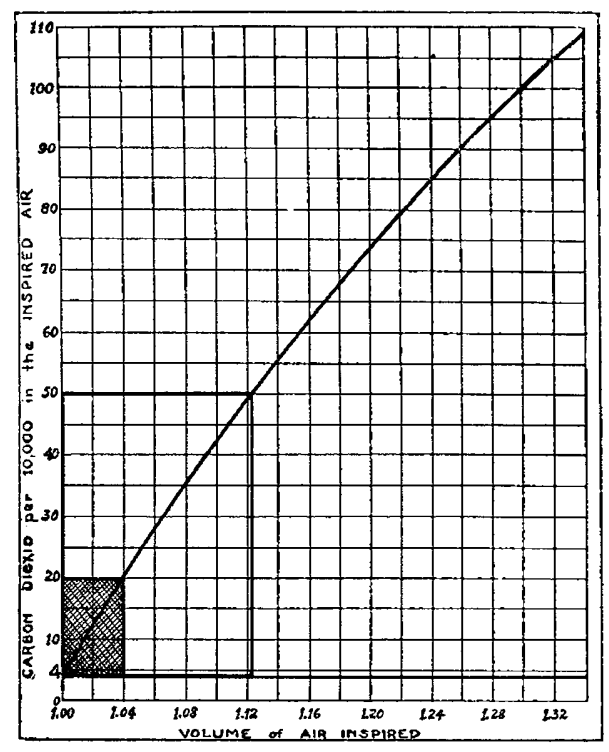

Fig. 23.- Showing the increasing depth of inspiration required to maintain a constant proportion of $\mathrm{CO}_{2}$ in the air of the lungs, while the production of this gas in the body remains constant and its proportion in the inspired air increases.

pulmonary ventilation is increased 50 per cent.; with 3 per cent. it is increased about 100 per cent.; with 4 per cent., about 200 per cent.; with 5 per cent., about 300 per cent.; and with 6 per cent., 500 per cent. With the last the alveolar tension of $\mathrm{CO}_{2}$ is, of course, above the normal, and this fact is signified by severe panting; but up to 3 per cent. in the inspired air the increase of breathing is scarcely noticed, unless muscular work is done, when the increased internal production of $\mathrm{CO}_{2}$ calls for a still greater increase of the pulmonary ventilation. The adjustments are automatic and go on without our consciousness, unless an excessive increase of breathing is demanded. 
If we are to maintain a constant proportion of $\mathrm{CO}_{2}$ in the alveolar air, each inspiration must be just large enough to dilute to the same degree the $\mathrm{CO}_{2}$ produced in the time interval of one respiration. If the amount of $\mathrm{CO}_{2}$ produced is constant, each breath will require the same amount of air to maintain the equilibrium. But if the air used for this dilution already contains some $\mathrm{CO}_{2}$ more will be required than if it had none; and as the amount of $\mathrm{CO}_{2}$ in the inspired air increases, an increasingly larger amount will have to be inhaled in order to maintain the alveolar constant of dilution. Mathematical calculation shows that the volume of pulmonary ventilation required to maintain a constant proportion of $\mathrm{CO}_{2}$ in the alveolar air, while the production of this gas by the body remains constant and its proportion in the inspired air increases, takes the form of an asymptotic curve. Figure 23 shows the form and dimensions of this curve of increasing depth of breathing for proportions of $\mathrm{CO}_{2}$ in the inspired air ranging from 0.04 to 1.1 per cent. ${ }^{11}$

The normal air contains not more than 0.04 per cent. of $\mathrm{CO}_{2}$. In well-ventlated rooms it is 0.06 or 0.08 per cent.; in poorly-ventilated rooms it may be 0.2 per cent. or more, but under very bad conditions it will rarely exceed 0.5 per cent. Including the ordinary amount of immediate reinspiration, the $\mathrm{CO}_{2}$ of the inspired air is not liable to exceed 0.5 per cent., and it will practically never go beyond 1.0 per cent. The small shaded quadrangle at the left lower corner of the chart, therefore, includes that portion of the curve corresponding to general contamination of the air in poorly-ventilated rooms, while the heavy outline beyond this includes the portion corresponding to this contamination plus the contamination due to immediate reinspiration. Four per cent. and a fraction over 12 per cent. are seen to be the respective limits of respiratory increase required to maintain the alveolar $\mathrm{CO}_{2}$ at a constant proportion, while 1.0 per cent. of $\mathrm{CO}_{2}$ in the inspired air requires only 30 per cent. increase of the depth of breathing to maintain the same constant. When we remember that the possibility of increase in the depth of inspiration is 400 or 500 per cent., and that by changing the

11. The unit volume of the tidal air when the inspired air is pure $\left(4 \mathrm{CO}_{2}\right.$ per 10,000 ), is assumed to be one-fifth of the volume remaining in the lungs at the end of expiration. This is about the average for quiet breathing. Hough and Douglas and Haldane $e^{7}$ have shown that increase in the pulmonary ventilation is brought about chiefly by increasing the depth of inspiration, supplemented when necessary by an increase in the rate of breathing and then by increased expiratory effort. The curve in the chart is constructed to depth of inspiration only, and assumes not only a constant rate of production of $\mathrm{CO}_{2}$ in the body, but a constant rate of breathing and a constant volume of air in the lungs at the end of expiration. The figures in the chart are essentially correct. for the increasing minute-volume of pulmonary ventilation, whatever the change in breathing by which this is brought about, when the unit is based on the removal by the outgoing tidal air of an average production of $\mathrm{CO}_{2}$ by the resting body, which is really the better way to express the relation. 
rate and the completeness of expiration the alveolar ventilation may be increased considerably more than 1,000 per cent., it is readily understood why this slight adjustment of 4 to 12 or even to 30 per cent. falls far below the limits of our conscious effort. It has already been stated, from the experiments of Haldane and Priestly ${ }^{4}$ that an actual increase of 100 per cent. in the pulmonary ventilation passes almost unnoticed.

In other articles I have reviewed ${ }^{12}$ the evidence concerning volatile poisons in the expired air, a subject which has always occupied a prominent place in discussions of the air we breathe. To one who had followed the large amount of experimental investigation by many workers it seemed that the question of their existence had been finally answered in the negative in 1905, when Flügge ${ }^{13}$ and his associates demonstrated clearly that the ill effects of confined air need no such hypothetical poison for their adequate explanation. It seemed for a time as if Weichardt, ${ }^{14}$ by the application of some new methods of investigation, had reopened the question; but Inabe ${ }^{\mathrm{x}}$ and Amoss, ${ }^{16}$ in attempting to confirm his work, have pointed out such faults of technic as practically to reverse his results and negative his conclusions. Moreover, the absence of these volatile poisons has been recently maintained by Hill, ${ }^{17}$ who has added much new evidence and a large measure of support for the contentions of Flügge.

On the other hand, the recent experiments of Rosenau and Amoss ${ }^{18}$ indicate that the condensed water vapour of the human breath may contain a trace of organic matter belonging to the protein group. When this fluid was injected into animals about one-fourth of them were so sensitized that a subsequent injection of human blood-serum gave a distinct anaphylactic reaction. This work will undoubtedly be repeated and confirmed, or another explanation offered. No volatile proteins have been previously known, none have been otherwise demonstrated in the breath, and the condensed water itself has no toxic effect when injected into animals. And when we remember that so small a quantity of egg albumin as 1-20,000,000th of a milligram ${ }^{19}$ is sufficient to confer a similar

12. Crowder. The Archives Int. Med., 1911, vii, 85; Trans. of the Section on Preventive Medicine and Public Health, Am. Med. Assn., 1911, 177; The Archives InT. Med., 1913, xi, 66.

13. Flïgge, Heymann, Paul, Erelenz: Ztschr. f. Hyg., 1905, xlix, 363, 388, 405,433 .

14. Weichardt: Arch. f. Hyg., 1908, Ixv, 252; 1911, lxxiv, 185.

15. Inabe: Ueber das Kenotoxin Weichardts in dem Ausathmungsluft, Ztschr. f. Hyg., 1911, lxviii, i.

16. Amoss: Organic Matter in the Expired Breath, Jour. of Exper. Med., 1913, xvii, 132.

17. Hill, Leonard: The Influence of Ozone in Ventilation. Jour. Royal Soc. Arts, 1912, lx, 344.

18. Rosenau and Amoss: Organic Matter in the Expired Breath, Jour. Med. Research, 1911, xxv, 35.

19. Wells: Studies of the Chemistry of Anaphylaxis, Jour. Infect. Dis., 1908, $\mathrm{v}, 449$. 
sensitization, it would seem that there may be possible sources of error quite difficult to control entirely.

But leaving all this aside, suppose for the moment that the breath does contain a protein - or any other waste organic substance - it still does not appear that a little reinspiration could be harmful. In the alveolar air this substance would necessarily be present in relatively high concentration, but always a lower concentration than the blood or tissues from which it comes. At the end of expiration it would fill the deadspace in like concentration, as must any gas excreted into the lungs, and the dead-space air is all drawn back with each breath as a part of normal breathing. We cannot directly increase the concentration of this hypothetical substance in the blood by breathing an atmosphere containing a lower concentration of it; we can only hinder its escape. But in this there is a necessary relation between any such hypothetical body in the expired air and the $\mathrm{CO}_{2}$, as well as a striking analogy to $\mathrm{CO}_{2}$ as a poison which has been clearly drawn by Sewall. ${ }^{20}$ We cannot rebreathe expired air without rebreathing $\mathrm{CO}_{2}$, and rebreathing $\mathrm{CO}_{2}$ causes deeper inspiration. The alveolar concentration of any gaseous constituent of the expired air must therefore be subject to the same laws of compensatory change in the pulmonary rentilation as are determined by the $\mathrm{CO}_{2}$. Our hypothetical substance would be regulated to whatever may be at any time its normal proportion simultaneously with, and by the action of, the $\mathrm{CO}_{2}$. And the quantitative values of the curve presented in Figure 23 will apply exactly to any other volatile excretion into the air-cells by substituting for $\mathrm{CO}_{2}$ the percentage of expired air represented by the $\mathrm{CO}_{2}$. I Let us assume that it were possible, by higher concentrations of our hypothetical organic body, to poison the animals producing it; it is possible also to poison them by $\mathrm{CO}_{2}$ - or even by oxygen - but far from being harmful in its normal concentration $\mathrm{CO}_{2}$ is a prime necessity; and the remarkable adaptibility of the respiratory function enables the body to maintain a normal concentration under a great variety of conditions. Regulation is automatic, and, according to our present physiologic conceptions, necessarily takes place. The adjustment demanded by the ordinary amount of reinspiration is relatively very small, and it would seem that it must lie well within the margin of safety which Melzer ${ }^{21}$ has so well described as belonging to all well-understood physiologic processes.

It is commonly, though erroneously, supposed that the good effects of efficient ventilation are due to the chemical purity of the air. When attention was called to the occurrence of immediate reinspiration it was looked on as a newly discovered source of impurity in the air we breathe.

20. Sewall: On What Do the Hygienic and Therapeutic Virtues of the Open Air Depend, Jour. Am. Med. Assn., 1912, lviii, 174.

21. Melzer: Factors of Safety in Animal Structure and Animal Economy, Harvey Lectures, New York, 1907-8, p. 139. 
To this previously unrecognized source of contamination was attributed much of the failure that has so often attended attempts to bring comfort out of ventilating procedures, and from this has arisen the "theory of displacement" in its application to ventilation. Accepting the old notion that chemical purity is a proper basis for ventilation standards, and assuming that reinspiration is necessarily harmful, some of the hygienists propose to handle the air supplied to a room in such a manner that the expired air will be immediately carried away from the face and cannot be rebreathed. It is asserted that if the new principle is applied a much smaller quantity of air than is demanded by the older quantitatve or dilution standards can be made to yield hygienic results. But small quantities of air do not lend themselves readily to maintaining the currents that have been shown to be necessary in order to accomplish the displacement aimed at. Or, if the necessary currents are maintained, and throughout a sufficient area to be effective, it becomes a physical necessity to recirculate the air; thus only delaying rather than preventing reinspiration, and reducing the system to one of simple dilution, which it is the avowed purpose to avoid. By actual experiment $I$ know that the plan most widely heralded does just this thing so far as the contamination of the air of a room is concerned, and it is improbable that immediate reinspiration is materially restricted. The theory of displacement does not sufficiently take into consideration that all animals possessing lungs ventilate them on a very simple principle of dilution; nor does the pure air theory sufficiently consider that the air of the lungs always remains highly contaminated with their own excretory gases, and that there is such an effective barrier as the dead-space against the lowering of the contamination.

If it is desired to prevent reinspiration, ways have been indicated by which this may be done. The results will be good, bad, or indifferent, according to the plan chosen; but in no case will the results, whether good or bad, depend on the fact that reinspiration is prevented. Within a wide range of variation in the purity of the air we breathe (in so far as the purity is effected by the products of respiration), the respiratory function is perfectly adapted to maintain its normal balance. The only apparent effect of rebreathing a little of our own expired air is a slightly deeper inspiration.

But ventilation is not a matter of little consequence because of this. It is still just as important as it has always been considered; the benefits of fresh air and the outdoor life are beyond question. But these measures should be carried out in the interest of the heat economy of the body rather than with regard to the chemical purity of the air we breathe. The good effects of the outdoor air depend on its coolness, its motion and its relative humidity. These physical qualities enable it to absorb the 
heat which is constantly being formed in the body, and which must be as constantly removed. Air that will take it up rapidly will stimulate healthy functions; air that takes it too slowly leads to sluggish metabolism, and if maintained will ultimately result in a low resistance to disease.

The rigor of a temperate or a colder climate makes of its inhabitants a house-dwelling race. They very commonly over-heat their houses, if not by fire and steam then by the heat of their own bodies; and when they do this they complain of poor ventilation, regardless of whether the air-supply is large or small. Whichever this may be, under any conditions that are likely to arise, there will still be oxygen in excess of every demand, and the $\mathrm{C}_{2} \mathrm{O}_{2}$ will still find a ready escape from the blood; but in an over-warm atmosphere the body heat will be stagnated and the consumption of oxygen by the tissue cells will be decreased. Ventilation is necessary in order to maintain the thermic balance of the body and to stimulate its chemical activity; and ventilation with cool air is especially desirable. A little extension of the dead-space beyond the tip of the nose is of no consequence. In spite of this extra contamination of the inspired air, the proportion of $\mathrm{CO}_{2}$ in the alveolar air will remain a little lower in a warm room than in the invigorating cold of the out-of-doors, as has been shown by Boycott and Haldane. ${ }^{22}$ It will remain so because metabolism is reflexly retarded by a warm aerial envelope, the consumption of oxygen by the tissues and the production of $\mathrm{CO}_{2}$ by them being much less in warm air than in cold.

That this discussion concerning the significance of reinspiration applies only to healthy persons scarcely needs to be added. The capacity of the lungs may become so restricted by disease that the slightest addi tion to their work is undesirable. But when we learn that they are still capable of performing the respiratory function with the capacity reduced to so little as one-sixth of the normal, ${ }^{23}$ the margin of safety is seen to be a very generous one.

22. Boycott and Haldane: The Effects of Low Atmospheric Pressure on Respiration, Jour. Physiol., 1908, xxxvii, 335.

23. Bernard et Mantoux: Capacité pulmonare minima compatible avec la vie, Jour. de physiol. exper., 1913. xv, 16; (Ed. Abstr. in Jour. Am. Med. Assn., $1913,1 x .1794)$. 